\title{
O PASSADO AINDA PRESENTE: RELATO DE EXPERIÊNCIA DE ESTÁGIO BÁSICO EM PSICOLOGIA
}

\section{ARTIGO ORIGINAL}

MAROSTICA, Thalia Paula ${ }^{1}$

ROSSAFA, Renata Garutti ${ }^{2}$

RECH, Bárbara David ${ }^{3}$

MAROSTICA, Thalia Paula. ROSSAFA, Renata Garutti. RECH, Bárbara David. O passado ainda presente: Relato de experiência de estágio básico em psicologia. Revista Científica Multidisciplinar Núcleo do Conhecimento. Ano 05, Ed. 11, Vol. 16, pp. 46-63. Novembro de 2020. ISSN: 2448-0959, Link de acesso: https://www.nucleodoconhecimento.com.br/sem-categoria/basico-em-psicologia

\section{RESUMO}

O Sistema Único de Saúde (SUS) é o resultado de um longo e árduo processo de construção política e histórica, constituindo-se atualmente como um campo que oferece inúmeras possibilidades de atuação para a Psicologia no sentido da promoção de saúde. O presente trabalho tem como objetivo socializar um relato de experiência vivenciado na disciplina de Estágio Básico em Psicologia no contexto de uma Unidade Básica de Saúde, da cidade de Cuiabá, Mato Grosso, bem como refletir acerca dos resultados encontrados em campo. Para tanto, foi realizado um estudo bibliográfico que permitiu uma breve construção do percurso histórico do sistema de saúde no Brasil e seu entrelaçamento com a Psicologia para, enfim, compreender os motivos pelos quais o modelo clínico individual se faz ainda tão presente nas práticas de saúde

\footnotetext{
${ }^{1}$ Graduação em Psicologia.

2 Orientadora. Graduação em Psicologia e Mestrado em Psicologia pelo Programa de Pós-graduação da Universidade Federal de Mato Grosso.

${ }^{3}$ Psicóloga.
} 
e, principalmente, ainda é tão frequente na atuação do Psicólogo, afastando-o das diretrizes atuais do SUS. Os resultados apontaram que a atuação do profissional psicólogo dentro da atenção básica apresenta-se como bastante desafiador, enfrentando diversos estigmas do passado que ainda se mostram presentes, impactando diretamente no andamento de uma ciência que só tem a promover saúde e bem-estar a população em geral.

Palavras chaves: Psicologia da Saúde, estágio, saúde, atenção básica.

\section{INTRODUÇÃO}

Quando um graduando ou profissional da área de saúde mental adentra em seu campo de estágio ou de trabalho, além de acessar um espaço de prestação de serviço especializado à pessoa com necessidades de tratamento e cuidados específicos em saúde mental, conforme versa Resolução № 298 de 1999 (BRASIL, 2002), está também adentrando em um campo marcado por histórias de avanços e retrocessos.

Após a Segunda Grande Guerra (1939-1945), diversos países ocidentais começam um processo de mobilização que resulta em acordos e políticas internacionais. Entre esses resultados temos o processo de reforma psiquiátrica que propunha uma revisão radical da lógica manicomial.

O principal documento norteador das políticas adotadas na área da saúde mental pelos governos dos países da América Latina foi a Declaração de Caracas, que resultou da Conferência Regional para a Reestruturação da Assistência Psiquiátrica no Continente, organizada pela Organização Pan-Americana da Saúde (OPAS) em novembro de 1990.

Para Silva et al. (2010), tal documento foi fundamental na construção dos princípios norteadores do que viria a ser o Sistema Único de Saúde (SUS) no Brasil, levando em conta a importância de aspectos psicológicos para a qualidade de vida e destacando o conceito de saúde como direito de todos e dever do Estado. 
Vale a pena destacar ainda a promulgação da Lei oㅜ 10.216 de 2001, conhecida como Lei da Saúde Mental. A partir de então, o foco de todo tratamento da pessoa com transtorno mental ou uso abusivo de álcool e outras drogas passa ser a reinserção do indivíduo em seu meio social.

De acordo com Freitas (2018), é a partir daí que surgiram Conferências Nacionais junto ao Sistema Único de Saúde (SUS) com o objetivo de tratar assuntos que promovam o surgimento de novas práticas e novos campos de trabalho para os profissionais da saúde mental, como os Centros de Atenção Psicossocial (CAPS) e os Núcleos de Atenção Psicossocial (NAPS).

Almeida (2019) faz um importante levantamento sobre a abrangência do CAPS no Brasil, informando que o número de unidades subiu no período de 2006 a 2017, de 673 para 2.462 em 2017. Um crescimento de 1.789 unidades CAPS em 11 anos.

Aliás, os CAPS têm se constituído como um núcleo fundamental na prestação de serviços de saúde mental do SUS. Ainda que a medicina nunca tenha deixado seu lugar privilegiado nos contextos de saúde, as várias conquistas decorrentes da reforma psiquiátrica permitiram que outras áreas de atuação obtivessem mais espaço, oferecendo cuidados aos pacientes que sofrem de transtornos mentais graves e persistentes em crianças, jovens e adultos.

Essa crescente implantação de CAPS até o ano de 2017, mesmo longe de corresponder ao ideal, seguia avançando em consonância com os movimentos de direitos humanos e de lutas da causa da saúde mental possibilitando desenvolver e fortalecer novas práticas na atenção básica de saúde, quanto se configurando um valioso campo de estágio e formação profissional.

É nesse complexo cenário que envolve a saúde pública brasileira que a Psicologia se insere cada vez mais como uma das profissões a serviço da promoção de saúde. Tal realidade acaba por impor aos cursos de graduação em Psicologia, bem como de outras profissões relacionadas à saúde, oferecer disciplinas que insiram os estudantes nesses campos de aprendizagem. 
Trabalhar no contexto da Saúde Básica se configura como uma prática bastante desafiadora para o psicólogo, visto que geralmente os estudantes de graduação são formados em uma perspectiva clínica, tendo desenvolvido habilidades que dizem respeito ao atendimento individual, mais condizentes com o modelo clínico tradicional, dentro das quatro paredes de um consultório, e ao adentrar em um ambiente que demanda uma prática coletiva, apresentam dificuldades de estratégias de atuação, além disso, ainda vivemos em uma cultura da cura, já que práticas preventivas de saúde ainda não são prioridade para a grande maioria dos governos.

Santos e Silva (2008), por exemplo, apresentam resultados qualitativos da inserção de alunos de psicologia no contexto dos cuidados em saúde do PSF na cidade de São Carlos, reafirmando a importância de se falar em saúde relacionando-a as complexidades subjetivas e a rede de determinantes, biológicos, psicológicos, sociais e culturais. Essa rede subjetiva gerou alguns desafios, o que as fez pautar a intervenção em torno de eixos que valorizam um fazer conjunto e coletivo, apostando na localidade e nas relações que nelas ocorrem.

Sicari et al. (2014), por sua vez, realizaram uma intervenção prática em psicologia da saúde em uma sala de espera da Unidade Básica de Saúde em Minas Gerais, utilizando-se da educação popular como instrumento, relatando como resultado uma experiência desafiadora, exigindo uma sensibilidade coletiva que proponha um olhar histórico e social do sujeito, mas que mesmo sob alguns olhares de insegurança de outros profissionais, a psicologia da saúde demonstra um lugar concreto a ser ocupado.

Nesse sentido, Nascimento; Manzini e Bocco (2006) concordam que é necessário reinventar práticas psicológicas, criando um constante estranhamento dos paradigmas e realidades que se apresentam como prontos, autorizando-nos a inventar, no cotidiano, estratégias que não obedeçam às fórmulas prescritas, mas que possibilite o exercício de autonomia em nossas análises e gestões do dia a dia.

Este artigo enfoca uma experiência de estágio básico em saúde de um curso de graduação em Psicologia, na cidade de Cuiabá, Mato Grosso, vivenciado em uma 
Unidade Básica de Saúde. A temática de intervenção da experiência de estágio aqui apresentada foi a não reincidência da gravidez, apresentando métodos contraceptivos através da educação em saúde. Além disso, aqui pretende-se também discutir os resultados e dificuldades encontradas no decorrer no processo e interpretá-los baseado em uma revisão de literatura, tecendo reflexões a respeito da prática do psicólogo na área em questão.

\section{METODOLOGIA}

Trata-se de um estudo descritivo, sendo relato de experiência no campo de estágio em saúde, vivenciado no primeiro semestre de 2019 em uma Unidade Básica de Saúde (UBS), como requisito curricular obrigatório de Estágio Básico III, do curso de graduação de Psicologia, da Universidade de Cuiabá (UNIC), em Mato Grosso.

Esse relato de experiência tem por objetivo descrever as ações desenvolvidas no campo de estágio em Psicologia, privilegiando um olhar reflexivo frente às ações propostas em campo e os desafios encontrados.

Além disso, para interpretação dos resultados e as discussões possíveis, empregouse como método uma pesquisa de abordagem qualitativa, do tipo revisão de literatura exploratória para realizar um estudo da história da Psicologia e da saúde pública no Brasil. A busca bibliográfica teve caráter nacional, sendo sistematicamente explorada nas bases SCIELO, PEPSIC e LILACS, utilizando como descritores de busca: "Psicologia" "Atenção Básica" e "Atuação".

Posteriormente, os resultados dessa busca foram organizados em tópicos gerais que permitissem construir uma linha do tempo contemplando os primórdios do sistema de saúde no Brasil e seu entrelaçamento com a Psicologia, ainda que brevemente. Tal construção é o que serve de fundamentação teórica para as reflexões deste relato de experiência.

Jacó-Vilela (2000), lembra que o estudo da história é o que possibilita compreender o contexto presente, para então, pensar um futuro: 
A história não é apenas uma série de fatos passados, mas algo em contínua construção, por se referir a uma sociedade sempre em movimento; estudá-la torna-se fundamental, porque possibilita a compreensão dos saberes e práticas atuais, iluminando assim nossas perspectivas futuras. (JACÓ-VILELA, 2000, p. 33).

O método de pesquisa histórico-bibliográfico empregado permitiu olhar para a experiência do estágio básico em saúde com outros olhos, possibilitando construir sentidos acerca dos atravessamentos inerentes ao campo e fazer desses mesmos atravessamentos possibilidades de aprendizado e compartilhamento de conhecimento.

\section{FUNDAMENTAÇÃO TEÓRICA}

\subsection{A POLÍTICA SANITÁRIA NO BRASIL}

Antes de recair o foco nas novas configurações da saúde pública no Brasil, convém abordar brevemente como as preocupações de natureza sanitárias passam a ganhar mais destaque. Oliveira (2012), afirma que é com a vinda da família real, no início dos anos 1800 , que se fortalece a necessidade da organização de uma estrutura sanitária mínima, capaz de dar suporte ao poder que se instalava na cidade do Rio de Janeiro.

Para Baptista (2007), já na Primeira República (1889-1930), a então capital do Brasil, passou por um quadro caótico de doenças graves que acometiam os moradores, o que acabou gerando prejuízo também para o comércio exterior, pois os navios estrangeiros deixaram de atracar no porto carioca em função da situação da cidade.

A partir disso, deu-se início a uma campanha com o objetivo de erradicar a febreamarela, feita por pessoas que exerciam atividades de desinfecção no combate ao mosquito. Outra medida tomada no mesmo período pelo presidente, foi a vacinação obrigatória anti-varíola em todo o território. Essas atividades marcariam o período como "modelo campanhista", onde obtiveram importantes vitórias no controle de doenças epidêmicas (OLIVEIRA, 2012). 
No governo Vargas, em 1930, ocorreu a criação do Ministério da Educação e Saúde Pública e do Ministério do Trabalho, Indústria e Comércio, dando início a um sistema de proteção ao trabalhador e questões relativas à saúde. Na mesma década, fundase o Conselho Nacional de Saúde e, na década de 50, a criação do Ministério da Saúde legitima o Estado como regulador soberano da saúde nacional, organizando postos de trabalho, fomentando indústrias de medicamentos, ensino profissionalizante, além de hospitais e ambulatórios (BAPTISTA, 2007).

Silva; Melo e Vasconcelos (1999), lembram que o golpe militar e o regime autoritário de 1964, impuseram aos serviços de saúde destinados à população brasileira uma significativa piora, notada principalmente pela parcela mais humilde da população, uma vez que a política de saúde se voltou para a expansão de serviços médicos privados.

A partir de 1970, as reivindicações populares e os marcos internacionais possibilitaram transformações concretas na esfera da saúde pública, como a repercussão da Conferência Internacional de Assistência Primária à Saúde, realizada em Alma-Ata, onde pautaram-se temas como a cooperação entre os diferentes setores da sociedade, assim como reivindicavam a universalização do direito à saúde, iniciando o processo de redemocratização da saúde no Brasil, que passava a assumir um sentido mais abrangente (BAPTISTA, 2007).

Ainda segundo a mesma autora, seguindo a progressão dessas mudanças, em 1980, foi realizada a VII Conferência Nacional de Saúde, que apresentou como propostas a reformulação da política de saúde, resultando em um sistema unificado, regionalizado e hierarquizado para o atendimento.

Para Silva et al. (2010), a VIII Conferência de Saúde, realizada em 1986, foi considerada um marco na política da saúde brasileira, onde foram aprovadas as diretrizes da universalização, e assim ficaram delineados os princípios norteadores do que viria a ser o Sistema Único de Saúde, assim como destacou o conceito de saúde como direito de todos e dever do Estado. 
É justamente no ano seguinte, em 1987, que ocorre no Brasil um marco na área da saúde mental: a I Conferência Nacional de Saúde Mental realizada no Rio de Janeiro. Após mais de uma década de mobilização do Movimento dos Trabalhadores em Saúde Mental (MTSM) e, como consequência dessa primeira conferência, o MTSM realiza o II Congresso Nacional, ainda no ano de 1987, enfatizando o tema "uma sociedade sem manicômios", transformando-se no que ficou conhecido até os dias de hoje como o Movimento da Luta Antimanicomial (AMARANTE; NUNES, 2018).

Destacar marcos importantes dessa história, conforme o que se segue abaixo, é ainda mais significativo no contexto de estágio básico em saúde na Psicologia, em que este estudo está situado, uma vez que permite compreender a construção da própria Psicologia enquanto profissão e como ocorreu a sua inserção na saúde básica.

\subsection{A POLÍTICA DE SAÚDE MENTAL NO BRASIL}

Por mais que a ideia de que os sujeitos estão classificados em dois grandes grupos, sendo o dos saudáveis/normais e dos doentes mentais, loucos ou anormais, pareça ter sido superada, o fato é que o estigma da "loucura" permanece em pleno século $\mathrm{XXI}$.

É bem verdade, contudo, que essa classificação já foi mais rígida, determinante e excludente do que é agora. Santos e Miranda (2015) ressaltam como a forma de exclusão aos portadores de doenças mentais pendurou-se por anos, e esses sujeitos doentes eram então abrigados em ambientes intitulados hospitais psiquiátricos, com o objetivo de resolver os problemas gerados pelos anormais, nesse contexto surgem os manicômios no Brasil, associando-se mais ao modelo prisional do que o terapêutico.

Em 1852 foi inaugurado no Rio de Janeiro o Hospício Dom Pedro II, o manicômio abrigava desviantes de todos os tipos, e o doentes mentais ganharam seus apelidos de "alienados", e a partir desse momento, foram construídos diversos asilos e manicômios em todo o país (FIGUEIRÊDO; DELEVATI; TAVARES, 2014). 
Para Freitas (2018), durante muitos anos, a assistência ao paciente psiquiátrico foi baseada em internação prolongada e exclusão do espaço social, as internações ocorriam mantendo-os em cativeiro, e o foco do tratamento não era a pessoa, e sim a doença, não havia respeito, e sim violência.

Vale lembrar que até 1939, a Psicologia não era uma disciplina integrante das grades curriculares dos cursos superiores na área da saúde no Brasil, conforme lembra Lourenço Filho (1971):

Então passou a constar do currículo de dois cursos de padrão federal, o de Filosofia e o de Pedagogia; e, como um e outro tivessem a duração de quatro anos, facilmente se compreende que graduados só se tornariam conhecidos, em número apreciável em 1944. (FILHO, 1971, p. 143).

O autor lembra ainda que esse período da história brasileira foi marcado por um grande movimento de industrialização, fazendo deslocar grandes grupos da população rural para as cidades. $O$ inchaço das cidades produziu novas demandas de organização e administração públicas, entre elas Lourenço Filho (1971) cita a ampliação do sistema de ensino e de oferta de serviços de saúde.

Até esse momento, contudo, a psicologia ainda não era uma profissão reconhecida. Os serviços de natureza psicológica eram oferecidos, principalmente, pela medicina orientada pelo modelo Clínico que substituiu no século XX o modelo epidemiológico. Significa dizer que o foco do cuidado não era mais a redução dos danos nas pessoas, mas sim o controle individual do estado de saúde dos indivíduos.

A Psicologia passa a ser reconhecidamente uma profissão de direito em 27 de agosto de 1962, com a Lei 4.119, sancionada pelo presidente João Goulart. Apenas dois anos após esse importante feito, o Brasil entra na Ditadura Militar (1964-1985), produzindo impactos na construção da identidade da profissão que não havia completado sequer dois anos de existência.

Bernardes lembra que, nesse período, o fazer psicológico era conduzido pelo "obscurantismo, pelas delações, pelos rompimentos com compromissos éticos, 
políticos e sociais." (BERNARDES, 2004, p. 95). É de se compreender os motivos pelos quais a Psicologia progrediu muito mais dentro dos enquadres do modelo clínico individualizado e particular, ficando distante de uma atuação mais presente nos serviços públicos.

Finalmente após a $2^{\mathrm{a}}$ Guerra Mundial, surgiram movimentos que não concordavam com a então tradicional forma de tratamento dos pacientes com transtornos mentais. No Brasil ocorreu em 1970 o Movimento dos Trabalhadores em Saúde Mental (MTSM), reivindicando mudanças no modelo, configurando então um movimento de luta antimanicomial, focalizando no cuidar humanizado das pessoas com transtornos mentais (OLIVEIRA, 2012).

De acordo com Figueirêdo; Delevati e Tavares (2014), nos anos de 1987 e 1992, foram realizadas duas Conferências Nacionais de Saúde Mental junto ao Sistema Único de Saúde (SUS), sendo tratados assuntos essenciais para o avanço da saúde mental, como o trabalho interdisciplinar. Tais discussões propiciaram o surgimento de novos modelos assistenciais, novas teorias e novas práticas.

Então a partir do final da década de 1980, surgiram as opções assistenciais, novos serviços como os Centros de Atenção Psicossocial (CAPS) e os Núcleos de Atenção Psicossocial (NAPS), dando forma a Reforma Psiquiátrica do Brasil, proporcionando atendimento psicológico, consultas médicas, serviço social, terapia ocupacional, dentre outros (FREITAS, 2018).

Outro marco essencial para o avanço no tratamento de transtornos mentais foi a promulgação da Lei № 10.216 de 2001, a Lei da Reforma Psiquiátrica, garantindo os direitos da pessoa doente mental e a busca pela manutenção de sua autonomia quanto aos tratamentos propostos. Nela constam:

Art. 4ํㅗ internação, em qualquer de suas modalidades, só será indicada quando os recursos extra-hospitalares se mostrarem insuficientes.

1ㅇ O tratamento visará, como finalidade permanente, à reinserção social do paciente em seu meio. 
$2^{\circ}$ O tratamento em regime de internação será estruturado de forma a oferecer assistência integral à pessoa portadora de transtornos mentais, incluindo serviços médicos, de assistência social, psicológicos, ocupacionais, de lazer, e outros. (BRASIL, p. 16, 2002).

As novas políticas públicas implementadas no Brasil foram possibilitando uma nova perspectiva aos profissionais da saúde e a inserção do psicólogo em novos espaços de atuação, antes restrito ao campo particular e individualizado de atendimento.

No tópico a seguir, outro elemento essencial para a sustentação da Reforma Psiquiátrica e as novas propostas de tratamento mental, bem como a valorização da Psicologia nesse contexto, será abordado: A Rede de Atenção Básica do Sistema Único de Saúde (SUS).

\subsection{A REDE DE ATENÇÃO BÁSICA E A ATUAÇÃO DO PSICÓLOGO}

No Brasil, a partir da Constituição de 1988, a saúde passa a ser um direito para todos e dever do Estado. Em 1990, o SUS é regulamentado, instituindo-se a Lei no 8.080/1990 (PAIM, 2009).

Dividido em três níveis de atenção, respectivamente da menor para a maior complexidade: o nível terciário que envolve procedimentos de alta complexidade, tecnologia e custo; o nível secundário que visam atender agravos à saúde que demandem especialistas ou recursos mais avançados que o nível primário, onde são realizados os procedimentos mais simplificados, capazes de dar resolutividade à maioria dos problemas comuns à população chamada de Atenção Básica. Ela é a porta de entrada do usuário no sistema de saúde, através das Unidades Básicas de Saúde (UBS), onde acontece a referência e contra referência para demais serviços especializados (KUSCHNIR et al., 2009).

Na Atenção Básica, começou a ser implementada a Estratégia de Saúde da Família (ESF), promovida pelo Ministério da Saúde. A equipe da ESF é composta por médicos, enfermeiros, técnicos em enfermagem e agentes comunitários de saúde. Profissionais como os psicólogos são vinculados ao Núcleo de Apoio à Saúde da Família (NASF), prestando apoio direto às UBS. 
Conforme Bernardes; Campos e Santos (2006), mesmo com um grande repertório de ações que podem ser desenvolvidas, como atividades em grupo, visitas domiciliares e oficinas, verifica-se ainda uma grande tendência à realização de atendimentos clínicos individuais. Possivelmente, resquícios dos primeiros passos que a Psicologia percorreu no Brasil da ditadura militar, caracterizada pelo modelo clínico individualizado.

Ronzani e Rodrigues (2006), lembram que a postura individualizada de tratamento dos usuários vai na contramão do que seria uma atuação comprometida com a comunidade, além de também se contrapor ao conceito de saúde que norteia o SUS que inclui os aspectos sociais nos cuidados.

Com isso, é necessário um trabalho contextualizado do psicólogo nesse nível de atenção à saúde, no sentido de fortalecer a promoção social. Para que tal objetivo se concretize, Amaral; Gonçalves e Serpa (2012) acreditam que o psicólogo deve se inserir na comunidade, no cotidiano dos moradores, compreendendo suas dinâmicas de maneira profunda e com comprometimento.

Nascimento; Manzini e Bocco (2006) concordam que é necessário reinventar práticas psicológicas, criando um constante estranhamento dos paradigmas e realidades que se apresentam como prontos, autorizando-nos a inventar, no cotidiano, estratégias que não obedeçam às fórmulas prescritas, mas que possibilite o exercício de autonomia em nossas análises e gestões do dia a dia.

Ou seja, o psicólogo está capacitado a trabalhar com saúde mental, possibilitando novas formas de se fazer saúde e incluindo a dimensão psíquica como integrante do ser humano cumprindo ao princípio da integralidade do SUS (COSTA; OLIVO, 2009).

A revisão histórica apresentada neste estudo, ainda que muito breve, permite verificar que, de 1962 até os dias atuais, muitas mudanças foram impostas ao processo de formação do profissional psicólogo. Conhecer o passado é o caminho para se compreender o presente das instituições em que os profissionais da área da saúde estão inseridos, sobretudos para àqueles que se aventuram em campos de estágios na condição de estudantes. 
A seguir, serão apresentadas algumas reflexões a respeito do contexto de estágio básico em saúde de um curso de graduação em Psicologia, na cidade de Cuiabá, Mato Grosso.

\section{RESULTADOS E DISCUSSÕES}

\subsection{O CAMPO DE ESTÁGIO, A INTERVENÇÃO E SEUS RESULTADOS}

Estar em campo de estágio básico de Psicologia em uma UBS apresentou-se como um desafio repleto de incertezas e imprevistos. Durante as primeiras semanas de observação, foram realizadas entrevistas informais com os agentes de saúde, enfermeira e médico, buscando conhecer mais sobre o funcionamento da unidade, assim como as principais preocupações relacionadas à equipe e comunidade.

A unidade em questão atende uma média de 3.700 pessoas e conta com cerca de 13 funcionários, cobrindo quatro bairros da cidade. De acordo com as atribuições e encargos da referida UBS, o profissional psicólogo não está diretamente vinculado à equipe, mas compõe o Núcleo Ampliado de Saúde da Família (NASF) em conjunto com algumas outras especialidades, onde a Unidade é o ponto de apoio da equipe.

O contato inicial com o campo de estágio foi de observações e entrevistas com a equipe de profissionais disponível. Desse contato, foi listado pelos funcionários uma crescente preocupação em relação à reincidência da gravidez, visto que a maioria das mulheres já possuíam em média 3 filhos e não apresentava, condições financeiras estáveis. Diante do que foi exposto, ficou então definido como demanda a ser trabalhada a "promoção de saúde e prevenção da não reincidência da gravidez".

Com o apoio de pesquisa documental e bibliográfica, foi elaborado um projeto interventivo com os respectivos temas: percepção em relação à gravidez, reflexão à perspectiva de futuro, métodos contraceptivos e planejamento familiar, autoestima, mitos e verdades em relação a gravidez e a importância da resiliência.

Inicialmente, o projeto de intervenção, estabeleceu como meta a realização de seis encontros semanais, no período da manhã, das $08 \mathrm{~h}$ às $11 \mathrm{~h}$, tendo como público alvo 
as gestantes. O convite foi feito por meio de divulgação de cartazes e folders fixados nas paredes do posto, além da distribuição de pequenos panfletos indicando os dias e horários das atividades para que os agentes de saúde pudessem entregar às mulheres em gestação no decorrer de suas visitas domiciliares.

Todos os encontros foram planejados a partir de dinâmicas de grupo, roda de conversa, atividades lúdicas, gincanas, enfim, atividades condizentes com o que propõe as políticas de saúde modernas. Porém, ao chegar o dia do primeiro encontro, nenhuma participante apareceu. Diante desse primeiro imprevisto, a alternativa encontrada foi improvisar: voltar no período da tarde para caso houvesse alguma participante que pudesse participar das propostas elaboradas. Porém, também não apareceu ninguém.

O contato com essa realidade foi levado para a supervisão do estágio, em que foram apontadas as primeiras necessidades de mudança no projeto. As novas estratégias construídas apostaram numa aproximação com a enfermeira da unidade, para levantar os dias e horários de pré-natais marcados pelas gestantes e, assim, adequar as intervenções ao horário das gestantes.

Foram realizadas as programadas seis visitas à unidade e também foram mantidos os temas propostos inicialmente, porém a ideia da construção de um grupo foi abandonada, adequando-se à tradicional abordagem individual.

Em cada encontro, foi possível abordar em média duas gestantes no período de espera do atendimento com o médico do pré-natal. A metodologia usada passou a ser a conversa informal com o apoio de panfleto com uma coletânea de orientações extraídas dos sites do Ministério da Saúde sobre os temas previamente determinados, que eram entregues para as participantes.

Entre os temas abordados, o planejamento familiar foi o de maior interesse pelas participantes, sobretudo no que se referia a laqueadura. Em todas as abordagens, esse era o assunto que as mulheres mais perguntavam informações sobre o processo burocrático para a realização da cirurgia. 
Observou-se que a abordagem individual possibilitou que o projeto pudesse ser concluído, atendendo às exigências do estágio. Porém, alguns questionamentos foram mobilizados na experiência de campo, gerando uma considerável frustração por parte das estagiárias: o que fez com que as mulheres gestantes não tenham aderido à proposta inicial, mesmo com toda a divulgação? Seria por uma dificuldade de se exporem? Será que eram esses os temas que elas gostariam de abordar?

Ainda que não seja possível responder a essas perguntas pelas mulheres, uma vez que essas questões ganharam nitidez apenas depois de encerrada a experiência de estágio, é possível analisá-las tomando a história como referência.

\subsection{DISCUSSÃO DOS RESULTADOS A PARTIR DA REVISÃO HISTÓRICA}

Ao assumir as dificuldades que frustraram as melhores expectativas alimentadas no campo de estágio, torna-se um exercício muito válido para a formação, pontuar e refletir sobre as possíveis ações que, se tomadas, poderiam ter auxiliado no enfrentamento dessas mesmas dificuldades encontradas na realização da propositura inicialmente elaborada.

Segundo Spink (2004), a atuação do profissional psicólogo, desde a década de 50, se baseava quase que exclusivamente na clínica tradicional e individual. Porém, conforme apresentado anteriormente, com o movimento da saúde coletiva no Brasil e após a implementação do SUS e de seus princípios, algumas mudanças foram vistas em sua atuação, sendo agora inseridos em campos de atuações na saúde.

Atualmente, alguns cursos de graduação já incluem em seu ensino aprendizagem métodos e matérias mais ligadas para a psicologia coletiva e social, inserindo o aluno nesse complexo e recente campo de trabalho. O que se observou foi que, mesmo com uma bagagem teórica bem organizada, ao adentrar na prática, a dificuldade de construir formas diferenciadas de intervenções, que levassem em conta a realidade e a coletividade, prevaleceram. 
Becker et al. (2004), ressalta a importância dos profissionais em garantir a potencialização e a participação ativa do sujeito no processo, implicando diretamente os organizadores da intervenção. Para tanto, Santos e Silva (2008), consideram ser de extrema importância o conhecimento aprofundado do público alvo, como questões socioeconômicas, escolaridade, ocupação, crenças, valores e aspectos sociais em geral.

Essa construção de vínculo entre quem propõe novos projetos e o público a ser beneficiado, não foi possível. Para tanto, seria necessário que um contato antecipado com as gestantes da UBS tivesse ocorrido, com a devida apresentação dos organizadores da intervenção.

Santos e Silva (2008), também ressaltam que para um trabalho efetivo, por se tratar de um âmbito coletivo, é importante que a prática seja interdisciplinar, ou seja, uma prática que possibilite uma articulação entre os profissionais e os saberes existentes. Mais uma vez, a experiência de campo ofereceu uma importante reflexão, a de como a tradição do passado do modelo clínico individualizado ainda é forte e presente no contexto regional da saúde pública.

Para que a proposta interventiva inicial tivesse chance de ser realizada, seria indispensável a integração da equipe efetiva da UBS, que já possui um vínculo estabelecido com as gestantes. Ao invés disso, o que se apresentou como mais viável, foi a abordagem individual das mulheres, realizando o trabalho de conscientização. Aliás, por diversas vezes, houve a sugestão de que fossem realizados atendimentos individuais dentro de uma sala e foi preciso explicar reiteradamente que o estágio se tratava de uma prática grupal para promoção da saúde e prevenção da doença.

De acordo com Oliveira; Silva e Yamamoto (2007), como a Psicologia não se incorpora com ênfase no contexto da Estratégia de Saúde da Família, acaba sendo alvo de críticas e confusões acerca de sua prática dentro do SUS.

É certo que os profissionais das outras áreas do saber consideram o profissional psicólogo um importante ator na formação da equipe, por outro lado, na maioria das vezes, essa mesma equipe atribui a função ao psicólogo de somente oferecer apoio 
emocional ao paciente, à família e à equipe, dificultando a divisão de papéis e a atuação efetiva do profissional, asseguram Saar e Trevisam (2007).

Tendo em vista aspectos marcantes do passado da Psicologia e como eles ainda hoje se fazem presente, talvez seja válido pensar que o psicólogo no contexto da saúde básica deva se antecipar. Dentro do contexto do estágio em questão, é possível listar algumas estratégias que poderiam ter sido tomadas, tais como acompanhar os Agentes de Saúde nas residências das gestantes e convidá-las pessoalmente para o projeto, além de se fazer presente na comunidade, entrando em contato com mercados e comércios locais para divulgação dos folders e cartazes.

Além dessas estratégias, por meio da equipe interdisciplinar, algumas ações poderiam ter sido planejadas em conjunto, abordando temas sugeridos pelas próprias mulheres, sugerindo exibições de filmes com rodas de conversas após o término, entre outros. Afinal, por mais que a equipe de profissionais da UBS já conhecesse bem a realidade daquelas mulheres, o fato de os temas partir delas, ainda que fossem os mesmos daqueles propostos inicialmente, ampliaria significativamente o vínculo e as possibilidades interventivas.

Nesse sentido, Santos e Silva (2008), concluem que para a atuação na saúde coletiva dentro do contexto psicológico, é importante considerar não somente os aspectos subjetivos do sujeito, pois por se tratar de uma rede, a prática deve se pautar na construção do fazer conjunto, valorizando todas interações existentes no campo. Lancetti (2006) ainda defende uma clínica com um fazer prático, que inicie de fora dos consultórios, em uma prática territorial, promovendo deslocamento subjetivos.

Yamamoto e Oliveira (2007), por sua vez, mencionam que a tendência do profissional de psicologia em privilegiar a estrutura clínica também deve ser considerada, pois não é nada fácil se desvencilhar da atuação dominante e tradicional da profissão, reconhecendo o quanto o passado, muitas vezes, não passou e continua produzindo efeito no presente.

\section{CONSIDERAÇÕES FINAIS}


Diante da discussão acerca dos resultados encontrados no processo do estágio aqui relatado, bem como o apanhado histórico apresentado, pode-se observar que não existem padrões e cronogramas a serem seguidos em uma atuação na saúde coletiva, demandando extrema habilidade e estratégias do profissional ali atuante.

Uma realidade que dá notícias de que o modelo clínico individualizado tradicional de atendimento à saúde permanece muito influente e solicitando do psicólogo uma atuação que corresponda a essas expectativas. Por esse motivo, deve-se, então, continuar apostando em uma clínica diferenciada, uma que deva se voltar a um sujeito universal, questionando os princípios tradicionais de atendimento.

Para tanto, se faz igualmente necessário que esse tema seja mais densamente abordado nos currículos das Universidades, e conte com programas de fomento a pesquisas, oportunizando que acadêmicos e profissionais sigam analisando o passado para compreender o presente e pensar um futuro que permita cada vez mais uma atuação preparada para lidar com um campo de múltiplas realidades e relações, como é o campo da saúde coletiva, comunitária.

Também se acredita que, na perspectiva de produção de conhecimento, estudos com este podem auxiliar e contribuir para que outros relatos sejam encorajados a vir a público e, principalmente, para colaborar com a formação de acadêmicos que irão ingressar neste campo de Estágio.

\section{REFERÊNCIAS}

ALMEIDA, José Miguel Caldas de. Política de saúde mental no Brasil: o que está em jogo nas mudanças em curso. Cadernos de Saúde Pública [online], Rio de Janeiro, v. $35, \quad$ n. $11, \quad$ p. $2-6,2019$. Disponível em: https://www.scielo.br/scielo.php?script=sci_arttext\&pid=S0102-311X2019001300502 Acesso em: 28/05/2020.

AMARAL, Marília dos Santos; GONÇALVES, Cristiane Holzschuh; SERPA, Monise Gomes. Psicologia Comunitária e a Saúde Pública: relato de experiência da prática Psi em uma Unidade de Saúde da Família. Psicol. Ciência e Profissão [online], [S.I], 
v. 32, n.2, pp.484-495 2012. Disponível em:

https://www.scielo.br/scielo.php?pid=S1414-

98932012000200015\&script=sci_abstract\&tIng=pt. Acesso em: 25/07/2020.

AMARANTE, Paulo; NUNES, Mônica de Oliveira. A reforma psiquiátrica no SUS e a luta por uma sociedade sem manicômios. Ciência \& Saúde Coletiva [online], Rio de Janeiro, v. 23, n. 6 , p. 2067-2074, 2018. Disponível em: https://www.scielo.br/scielo.php?pid=S1413-

$81232018000602067 \&$ script=sci_abstract\&tIng=pt. Acesso em 25/07/2020.

BAPTISTA, Tatiana Wargas de Faria. História das políticas de saúde no Brasil: a trajetória do direito à saúde. In: MATTA, Gustavo Corrêa; PONTES, Ana Lúcia Moura. (Org.). Políticas de saúde: a organização e a operacionalização do Sistema Único de Saúde. Rio de Janeiro: Escola Politécnica de Saúde Joaquim Venâncio/Fiocruz, 2007, p. 29-60.

BECKER, Daniel; et al. Empowerment e Avaliação Participativa em um Programa de Desenvolvimento Local e Promoção da Saúde. Ciênc. saúde coletiva, Rio de Janeiro, 9(3), p. 655-667, 2004. Disponível em: https://www.scielo.br/scielo.php?pid=\$1413-81232004000300017\&script=sci_arttext. Acesso em 25/07/2020.

BERNARDES, Jefferson de Souza. 0 debate atual sobre a formação em Psicologia no Brasil: permanências, rupturas e cooptações nas políticas educacionais. 2004. 268 p. Tese. (Doutorado em Psicologia) - Pontifícia Universidade Católica de São Paulo, São Paulo, 2004.

BERNARDES, Jefferson de Souza; CAMPOS, Florianita C. Braga; SANTOS, Liliana. O psicólogo no SUS: suas práticas e as necessidades de quem o procuram. In: SPINK, Mary J. Paris. A Psicologia em diálogo com o SUS: prática profissional e produção acadêmica. São Paulo: Casa do Psicólogo, 2006.

BRASIL. Legislação em Saúde Mental 1990-2002. 3ํo ed. Brasília: Ministério da Saúde, 2002. 
https://conselho.saude.gov.br/biblioteca/livros/legislacaosaudemental2002completa.p df. Acesso em: 01/08/2020.

. Lei oㅜ 10. 216, de 06 de abr. de 2001. Dispõe sobre a proteção e os direitos das pessoas portadoras de transtornos mentais e redireciona o modelo assistencial em saúde mental. Diário Oficial da União: Brasilia, DF, ano 2001. Disponível em http://www.planalto.gov.br/ccivil_03/leis/leis_2001/110216.html. Acesso em: 01/08/2020.

COSTA, Diogo Faria Corrêa da; OLIVO, Vânia Maria Fighera. Novos Sentidos para Atuação do Psicólogo no Programa Saúde da Família. Ciência e Saúde Coletiva [online]. Rio de Janeiro, v. 14, supl. 1, p. 1385-1394, 2009. Disponível Em: https://www.scielo.br/scielo.php?pid=S1413-

$81232009000800011 \&$ script=sci_abstract\&tlng=pt. Acesso em: 25/07/2020.

FIGUÊIREDO, Marianna Lima Rolemberg de; DELEVATI, Dalnei Minuzzi; TAVARES, Marcelo Góes. Entre loucos e manicômios: história da loucura e a reforma psiquiátrica no Brasil. Cadernos de graduação, Maceió, v. 2, n. 2, p. 121-126, 2014. Disponível em: $\quad$ https://periodicos.set.edu.br/index.php/fitshumanas/article/view/1797/1067. Acesso em: 25/07/2020.

FREITAS, Bismarck Liandro de. A evolução da Saúde Mental no Brasil: Reinserção Social. Rev. Cientifica Semana Acadêmica, Niterói, v. 126, n. 1, p.1-15, 2018. Disponível em: https://semanaacademica.org.br/artigo/evolucao-da-saude-mental-nobrasil-reinsercao-social. Acesso em: 25/07/2020

JACÓ-VILELA, Ana Maria. Anais do I Seminário de Historiografia da Psicologia. 1 ed. São Paulo: GEHPAI/Fapesp, 2000. 109 p.

KYSCHNIR, Rosana. et al. Configuração da Rede Regionalizada e Hierarquizada de Atenção à Saúde no Ambito do SUS. In: OLIVEIRA, Roberta Gondim de; GRABOIS, Victor; JÚNIOR, Walter Vieira Mendes. Qualificação de Gestores do SUS. Fundação Oswaldo Cruz: Rio de Janeiro, 2009, p. 141-149. 
LANCETTI, Antonio. Clínica peripatética. 1 ed. São Paulo: Hucitec, 2006. 128 p.

LOURENÇO FILHO, Manuel Bergstrom. A Psicologia no Brasil nos últimos 25 anos. Arquivos Brasileiros de Psicologia Aplicada, Rio de Janeiro, v. 23, n. 3, p. 143151, 1971.

Disponível

em:

http://bibliotecadigital.fgv.br/ojs/index.php/abpa/article/view/16751/15557. Acesso em: 05/07/2020.

NASCIMENTO, Maria Lívia do; MANZINI, Juliane Macedo; BOCCO, Fernanda. Reinventando as Práticas Psi. Rev. Psicologia Social, Porto Alegre, v. 18, n.1, p.1520 , 2006.

Disponível

em: https://www.scielo.br/scielo.php?pid=S010271822006000100003\&script=sci_abstract \&tlng=pt. Acesso em: 25/07/2020.

OLIVEIRA, André Luiz de. História da saúde no Brasil: dos primórdios ao surgimento do SUS. Encontros Teológicos, Uberlândia, v.27, n. 61, p. 31-42, 2012. Disponível em: https://facasc.emnuvens.com.br/ret/article/view/198. Acesso em: 25/07/2020.

OLIVEIRA, Isabel Fernandes de; SILVA, Fabiana Lima; YAMAMOTO, Oswaldo Hajime. H. A psicologia no Programa de Saúde da Família (PSF) em Natal: espaço a ser conquistado ou um limite da prática psicológica?, Aletheia, Canoas, n. 25, p. 0519 , jun. 2007.

http://pepsic.bvsalud.org/scielo.php?script=sci_arttext\&pid=S1413$03942007000100002 \&$ Ing=pt\&nrm=iso. Acesso em: 25/07/2020.

PAIM, Jairnilson Silva. Uma análise sobre o processo da Reforma Sanitária brasileira. Saúde em Debate, Rio de Janeiro, v. 33, n.81, p. 27-37, 2009. Disponível em: http://pepsic.bvsalud.org/scielo.php?script=sci_arttext\&pid=S141303942007000100002. Acesso em: 25/07/2020.

RONZANI, Telmo Mota; RODRIGUES, Marisa Cosenza. O Psicólogo na Atenção Primária à Saúde: contribuições, desafios e redirecionamentos. Psicologia: Ciência e Profissão, Brasilia, v. 26, n.1, 132-143, 2006. Disponível em: 
http://pepsic.bvsalud.org/scielo.php?script=sci_arttext\&pid=S141498932006000100012. Acesso em: 25/07/2020.

SAAR, Sandra Regina da Costa; TREVIZAN, Maria Auxiliadora. Papéis profissionais de uma equipe de saúde: visão de seus integrantes. Revista Latino-americana de Enfermagem, [S.I], v.15, n.1, p.106-112, 2007. Disponível em: https://www.scielo.br/scielo.php?script=sci_abstract\&pid=S010411692007000100016 \&lng=pt\&nrm=i. Acesso em: 25/07/2020.

SANTOS, Júlia Amorim; SILVA, Marcela Contessotto da. Psicologia Social na Atenção Básica: relatório das atividades desenvolvidas no estágio. 2008. 51 f. Relatório de estágio (Graduação em Psicologia) Universidade Federal de São Carlos, São Carlos, 2008. Disponível em: http://newpsi.bvspsi.org.br/tcc/JuliaSantos_MarcelaSilva.pdf. Acesso em: 25/07/2020.

SANTOS, Pedro Antônio N. dos Santos; MIRANDA, Marlene B. S. O percurso histórico da Reforma Psiquiátrica até a volta para casa. 2015. $18 \mathrm{f}$. Trabalho de Conclusão de Curso (Especialização em atenção básica à saúde mental) - Escola Bahiana de Medicina e Saúde Pública, Salvador, 2015. Disponível em: https://repositorio.bahiana.edu.br:8443/jspui/handle/bahiana/366. Acesso em: 01/08/2020.

SICARI, Amaral Aline. et al. Psicologia e Educação Popular: uma estratégia de promoção da saúde. Revista de Educação Popular, v. 13, n. 1, p. 135-146, 2014. Disponível em: http://www.seer.ufu.br/index.php/reveducpop/article/view/26968. Acesso em: 01/08/2020.

SILVA, Ana Paula Freitas da; MELO, Livía Silas de; VASCONCELOS, Eymard Mourão. Educação Popular e a Atenção a Saúde da Família. 1 ed. São Paulo: Hucitec, 1999. 342 p.

SILVA, Cristiane Maria da Costa. et al. Educação em Saúde: uma reflexão histórica de suas práticas. Revista Ciência e Saúde Coletiva, Ciênc. saúde coletiva, Rio de Janeiro, v. 15, n. 5, p. 2539-2550, 2010. Disponível em: 
https://www.scielo.br/scielo.php?script=sci_arttext\&pid=S1413-81232010000500028. Acesso em: 01/08/2020.

SPINK, Mary-Jane. A formação do psicólogo para a atuação em instituições de saúde. Psicologia social e saúde: práticas, saberes e sentidos. 2 ed. Petrópolis, RJ: Vozes, 2004.

Enviado: Agosto, 2020.

Aprovado: Novembro, 2020. 